\title{
Performance Evaluation of Silica gel /water Adsorption Cooling Unit
}

\author{
A. Khalil ${ }^{1}$, S. A. El-Agouz ${ }^{1}$, Y. A. F. El-Samadony ${ }^{1}$, M. A. Sharaf ${ }^{2}$ \\ ${ }^{1}$ Mech. Power Eng. Dep., Faculty of Eng., Tanta University, Egypt \\ ${ }^{2}$ Mech. Eng. Dep., Faculty of Eng., Kafr elsheikh University, Egypt \\ S.khalilk@yahoo.com,elagouz2011@yahoo.com, samadony25@yahoo.co.uk, \\ mech.enge@yahoo.com
}

\begin{abstract}
In the present work, an experimental study of adsorption refrigeration unit with modified adsorption bed is obtained. Silica gel and water are used as a working pair in the adsorption refrigeration unit. Hot air is used for Silica gel regeneration. The effect of evaporator pressure, evaporator inlet water temperature, initial Silica gel temperature, and hot air regeneration temperature and mass flow rate on the unit coefficient of performance is studied. It has been found that increase of hot air regeneration temperature and inlet evaporator temperature increases the unit refrigeration capacity and coefficient of performance. On the other hand, a decrease of Silica gel temperature and evaporator pressure increases the unit refrigeration capacity and coefficient of performance. The results confirm that this kind of adsorption chiller is an effective refrigerating machine, it can be used for air conditioning or producing chilling water since it make a reduction in the chilling water temperature more than $10^{\circ} \mathrm{C}$ in 3 minutes. In addition the present unit with its novel adsorber gives higher coefficient of performance than that was obtained from the similar previous models
\end{abstract}

Keywords: Adsorption refrigeration, Silica gel-water pair, Cooling unit, Experimental study

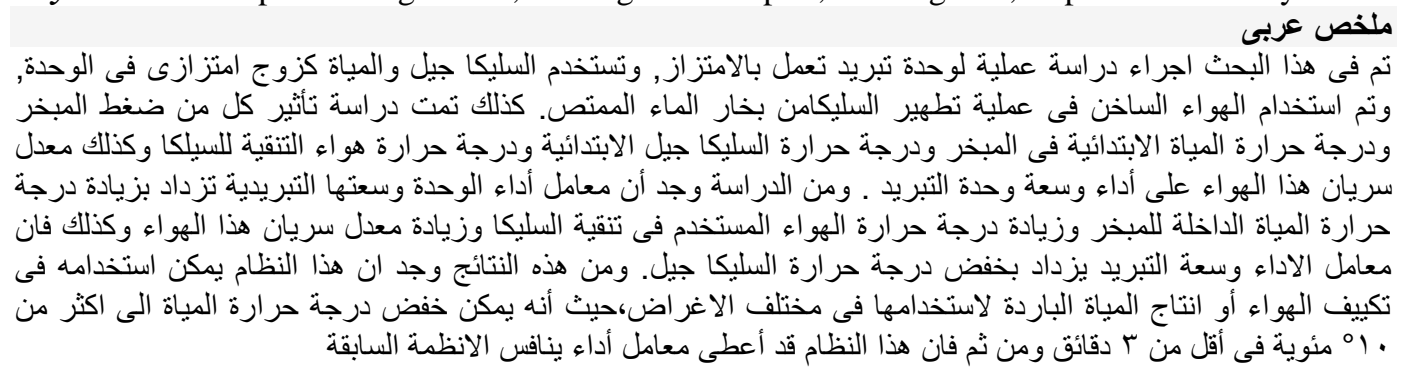

\section{INTRODUCTION}

The major attraction points of adsorption cooling or refrigeration technology are that it is noiseless, non-corrosive, environmentally friendly and powered entirely or partly by low grade energy such as solar energy, bioenergy, and low-grade waste heat, etc. Therefore, adsorption systems have attracted research interests as an alternative cooling solution. However, the main limitation in the commercial application of adsorption systems is its rather low coefficient of performance.

In order to improve the performance of such cooling systems, several advanced cycles have been proposed. Yongling [1] studied the influence of operating temperatures on the performance of single bed activated carbon and methanol machine. He found that when the hot water inlet temperature was increased, the specific cooling power (SCP) of performance is increased at every operation condition.
Chang et al [2] built a flat-tube type heat exchanger to be used for adsorption beds in order to increase the heat transfer area and improve the heat transfer ability between the adsorbent and heat exchanger fins. They obtained that the system can achieve a coefficient of performance (COP) of 0.45 . Louajari et al. [3] studied the optimal design of cylindrical finned adsorber for solar adsorption cooling machine working with activated carbon/ammonia pair. They found that at an evaporator temperature of $0{ }^{\circ} \mathrm{C}$ and regeneration temperature of $97^{\circ} \mathrm{C}$, the optimal number of fins is 5 or 6 at which the coefficient of performance would be 0.0106 .

Because one bed systems have low system performance in terms of SCP and COP and can only provide cooling intermittently. To solve this problem, two or more beds have been proposed by different researchers. Simple two-bed adsorption refrigeration cycle which was fabricated by Kasidid [4], to develop specific cooling power (SCP) and COP of 
$601 \mathrm{~W} / \mathrm{kg}$ and 0.32 respectively at desorption temperature $70^{\circ} \mathrm{C}$. Mitsuhiro et al. [5] studied the cooling performance of adsorption heat pump with fin-type silica gel tube module. It was found that the cooling output reached a maximum value of $2.67 \mathrm{~kW}$ and COP was 0.32 .

A novel silica gel-water adsorption chiller with two chambers has been built in Shanghai Jiao Tong University (SJTU) by Wanga et al. [6 and 7] and Zaizhong et al. [8]. Their improved chiller composed of three vacuum chambers, two adsorption /desorption vacuum chambers and one heat pipe working vacuum chamber. They found that the refrigerating capacity and the COP of the chiller are $8.69 \mathrm{~kW}$ and 0.388 respectively, at heat source temperature of $82.5^{\circ} \mathrm{C}$. Also, Yanlin [9] invented an adsorption type refrigerator which had four absorbers in the system with two absorbers different in adsorption capacity from the others.

Other methods had been sought to provide low cost heat recovery with the adsorption cooling systems integrated in such a manner to provide an overall stable and continuous operation [10]. The heat recovery cycle can shorten the cycle time and increase the SCP and COP. Yong and Ruzhu [10] was found that if time for heat recovery was increased in order to get more heat recovered, the performance of the system may drop, especially for SCP.

Wang et al. [11] developed an adsorption refrigeration system (Ice Maker) by combining the mass and heat recovery processes. They presented experimental results of the system operating with an intermittent cycle and a cycle time of 35 minutes. The thermal conditions used to test the cycle were: $115^{\circ} \mathrm{C}$ heat source, $22^{\circ} \mathrm{C}$ heat sink and the evaporator temperature corresponding to the chilled ethylene glycol temperature was $-7^{\circ} \mathrm{C}$. The results showed that the COP reaches to 0.07 whereas the SCP (specific cooling power) was $11 \mathrm{~W} / \mathrm{kg}$ by activated carbon.

Saha [12] built a dynamic modeling of a single effect two-bed adsorption chiller utilizing the composite adsorbent " $\mathrm{CaCl} 2$ confined to silica gel" as adsorbent and water as adsorbate. From numerical simulation, it was also found that the cooling capacity can be increased up to $20 \%$ of the parent silica gel-water adsorption chiller and the coefficient of performance (COP) can be improved up to $25 \%$ at optimum conditions.

In the present study, an experimental modified silica gel/water adsorption refrigeration unit has been designed and installed to evaluate the effect of design and operating parameters on the unit performance. Several objectives are formulated to address the overall goal of the present study; evaluation of the effect of design and operating parameters on the performance of the modified unit. These objectives are:

1. Design and installation of a modified silica gel/water adsorption refrigeration unit with a new adsorber design.

2. Study the effect of the effect of evaporator pressure, evaporator inlet water temperature, initial Silica gel temperature, and hot air regeneration temperature and mass flow rate on the unit coefficient of performan.

\section{EXPERIMENTAL WORK}

\subsection{System description}

The system consists of an insulated evaporator, insulated generator, vacuum pump, blower, electrical heater and manual valves. The schematic diagram of the test rig is shown in Fig. 1 and photographs of the experimental test rig and the instrumentation attached to the test section is presented in Figure. 2.

The present generator or adsorber bed design is different from packed beds which were proposed by many other researchers. The present Adsorber bed consists of four concentric stainless steel net tubes (2 $\mathrm{mm}$ grad size). Silica gel grain with average radius of $3 \mathrm{~mm}$ is filled the volume between the concentric stainless steel net tubes. In the present design, sufficient void volume is introduced such that evaporated refrigerant can simultaneously reach a large amount of absorbent in a short period of time. Adsorber geometry and dimensions are shown in Fig .3 and Fig.4 respectively.

Silica gel-water has been selected as adsorbent adsorbate pair because of the low regeneration temperature of silica gel and the high latent heat of vaporization of water. Additionally, this working pair is non-toxic and environment friendly. The average radius of silica gel grain was $3 \mathrm{~mm}$, and the properities of silica are taken from Solar Energy Research Institute [13].

A vacuum pump was used to evacuate the evaporator and adsorber. A blower is used to supply the system with the required preheated air using an electrical heater

\subsection{System operation}

The proposed adsorption cooling system contains two loops, namely the Silica gel adsorption /cooling loop and the hot air Silica gel regeneration loop.

The Silica gel adsorption cooling loop consists of vacuum pump, galvanized steel evaporator, pressure transducer, control manual valves, adsorber, electronic balance and thermocouples.

The testing procedures were conducted as follows: first weight the mass of the water in the evaporator, degas the generator continuously using vacuum pump (valves V1 and V3 were opened), evacuate the evaporator until water little bit boiling, evacuate the generator (Open valves V1 and V3), 
finally, Open valve V2 and valve V3 until the adsorbent bed reaching adsorption equilibrium.

The hot air Silica gel regeneration loop consists of generator, blower, electrical heater (1500 $\mathrm{W})$, thermocouples, air flow meter and manual valves. In this loop valves V2 and V3 are closed. Air is flown from the blower on the electrical heater. Temperature controller was used to adjust the desired regeneration temperature. Finally, flow passes through the adsorber (V4 and V5 are opened) until Silica gel is regenerated.

\subsection{Measuring instruments and accuracy}

To know the input, output and the process conditions many measurements are required. In the present study, vacuum pressure, water evaporator temperature, Silica gel temperature, inlet and outlet hot regenerative air temperature, humidity and hot air flow rate were measured.

Vacuum pressure is measured by using pressure transducer with range $(0-1$ bar abs $)$ and accuracy of $\pm 100 \mathrm{~Pa}$. The evaporator water weight is measured by using a digital balance with range $(10 \mathrm{~g}$ $15 \mathrm{~kg})$ and accuracy of $\pm 0.5 \mathrm{~g}$. The hot air velocity is measured using Anemometer with range (0.1 - 30 $\mathrm{m} / \mathrm{s}$ ) and accuracy of $\pm 0.1 \mathrm{~m} / \mathrm{s}$. Three $\mathrm{K}$ - type thermometers with range $-50^{\circ} \mathrm{C}$ to $+1300^{\circ} \mathrm{C}$ are used to measure temperature of water evaporator and Silica gel. These thermocouples are attached to a Digit-Sense 12 Channel Scanning Bench Top Thermometer with scale division of $0.1{ }^{\circ} \mathrm{C}$. The temperature and humidity of inlet and outlet hot air is measured by using USB data logger with range $(0-$ $120{ }^{\circ} \mathrm{C}$ ) and accuracy of $\pm 0.1^{\circ} \mathrm{C}$ for temperature while range $(0-100 \%)$ and accuracy of $\pm 1 \%$ for humidity.

\section{SYSTEM PERFORMANCE \\ CALCULATIONS}

System refrigeration capacity and coefficient of performance will be calculated as follows: follows:

Refrigeration capacity is calculated as

$Q_{c}=\frac{\left.m_{w} C_{p}\right)_{w}\left(T_{w, \text { in }}-T_{w, \text { out }}\right)}{t}$

Where: $\mathrm{m}_{\mathrm{w}}$ is the mass of water, $\left.\mathrm{C}_{\mathrm{p}}\right)_{\mathrm{w}}$ is the specific heat of water, $\mathrm{T}_{\mathrm{w}, \text { in }}, \mathrm{T}_{\mathrm{w}, \text { out }}$ are the inlet and outlet of water and $t$ is the time.

Heating power is calculated as follows:

$\left.Q_{h}=\dot{m}_{a} C_{p}\right)_{a}\left(T_{a, \text { in }}-T_{a, \text { out }}\right)$

Where: $\dot{\mathrm{m}}_{\mathrm{a}}$ is the mass flow rate of air, $\left.\mathrm{C}_{\mathrm{p}}\right)_{\mathrm{a}}$ is the specific heat of air, and $\mathrm{T}_{\mathrm{a}, \text { in }}, \mathrm{T}_{\mathrm{a} \text {,out }}$ are the inlet and outlet of air.

Coefficient of performance is calculated as follows:

$$
C O P=\frac{Q_{c}}{Q_{h}}
$$

\section{RESULTS AND DISCUSSION}

A detailed study of the factors affecting the performance of adsorption refrigeration is made in order to achieve the optimum design. This study included the effect of the initial temperature of water in the evaporator, initial temperature of the solid desiccant before the adsorption processes, hot air temperature and hot air mass flow rate during the regeneration process.

Figures (5) and (6) show the general trend of evaporator and adsorber temperature with time. It can be observed from figure (5) that the evaporator temperature decreases with time during adsorption process. This is because latent heat for evaporation of water reduces the residual water temperature. Also, it can be seen from figure (6) that adsorber temperature increases with time during adsorption process. This is because adsorption is an exothermic process.

\subsection{Effect of evaporator inlet water temperature}

Figure 7 illustrates the variation of the temperature of water in the evaporator with time for different inlet temperature in the evaporator. From this figure it can be seen that evaporator water temperatures are always decrease with time in adsorption process and the rate of this decrease is increased as initial water temperature in the evaporator is increased. This is because as the water temperature increase its vapour pressure increases and this enhance the adsorption processes from water to silica gel. Figure 8 illustrates the variation of the amount of decreasing water temperature in the evaporator with initial water temperature. From this figure it can be seen that as the evaporator inlet water temperature increases, the difference between evaporator inlet water temperature and evaporator outlet water temperature increases.

Figure 9 illustrates the variation of the cycle coefficient of performance (COP) with inlet water temperature in the evaporator. While Figure 10 illustrates the variation of the cycle refrigeration capacity (Qc) with inlet water temperature in the evaporator. It can be seen from these figures that as the inlet water temperature increases, COP and Qc increase. Also, when inlet water temperature in the evaporator is increased from $15.4{ }^{\circ} \mathrm{C}$ to $36.8{ }^{\circ} \mathrm{C}$, COP and Qc are increased by about $156 \%$ and $216 \%$ respectively.

Figure 11 illustrates the variation of the cycle coefficient of performance with initial adsorber temperature. While figure 12 illustrates the variation of the cycle refrigeration capacity with initial adsorber temperature. It can be seen from these figures that as the initial adsorber temperature increases cycle coefficient of performance and refrigeration capacity decrease. This is because adsorption process is perfect for low silica gel temperature to make silica adsorp more water vapor and Vis versa increasing silica gel temperature 
reduces adsorption of water vapor which decreases the performance of the adsorption processes. When initial adsorber temperature is increased from 21.6 to $38{ }^{\circ} \mathrm{C}$, COP and Qc are decreased by about $49 \%$ and $43 \%$ respectively.

\subsection{Effect of initial adsorber temperature}

Figure 13 illustrates the variation of the temperature of water in the evaporator with time for different initial adsorber temperature. It can be seen from this figure that as the initial adsorber temperature increases the difference between evaporator inlet water temperature and evaporator outlet water temperature decreases. Hence, COP and Qc will be decreased. This is because as the adsorber (Silica gel) temperature increases its ability to adsorb water vapour decreases. Therefore, it could be concluded that it is better to cool the adsorber (Silica gel) down during the adsorption processes. This is because adsorption processes is an exothermic process which increase adsorbent temperature as previously shown in Fig. 6.

\subsection{Effect of air regeneration temperature}

Figure 14 illustrates the variation of the cycle refrigeration capacity with air regeneration temperature at different evaporator inlet water temperatures. However, Figure 15 illustrates the variation of the cycle coefficient of performance with air regeneration temperature. It can be seen at different evaporator inlet water temperatures that as the air regeneration temperature increases cycle coefficient of performance and refrigeration capacity increase. This is because as air regeneration temperature increases the silica gel will be dried enough to adsorb water vapour for the following adsorption process which increases the performance. Figure 16 illustrates the variation of the system coefficient of performance with initial evaporator water temperature at different air regeneration temperature. It can be seen from this figure that for identical initial evaporator water temperature, as the air regeneration temperature increases, system coefficient of performance increases.

\subsection{Effect of air regeneration mass flow rate}

Figure 17 illustrates that as hot air mass flow rate increases, the evaporator water temperature difference increases with time at the same operating conditions. This is because as hot air mass flow rate increase, more water molecules can be removed from silica gel.

\subsection{Comparison with former works}

The trend of the COP and SCP for the present chiller is quite similar to that for the former conventional chillers. To see the reliability of the present system a comparison between the performance of the present system and some former systems was made. The comparison was made at nearly typical working conditions. However, the method of regeneration and the adsorber design may be different as shown in Table 1. It can be noted from Table 1 that the coefficient of performance of the present system with its novel adsorber design is quite higher than that for the conventional chiller. Therefore, the present novel chiller is another effective cooling machine compared with the conventional chiller and the improved chiller.

\section{CONCLUSIONS}

The following concluding remarks can be drawn from the present experimental study and its analysis: The main feature of the proposed chiller is the ability to be driven by relatively low temperature heat source. The chiller can utilize the fluctuated heat source temperature between 60 and $80{ }^{\circ} \mathrm{C}$ to produce effective cooling. Also, we can conclude that:

- Cooling capacity and coefficient of performance increases with the increase of hot air mass flow rate and regeneration temperature and evaporator inlet water temperature. On the other hand, cooling capacity and coefficient of performance decreases with the increase of initial silica gel temperature in the adsorption processes.

- To increase silica gel uptake of water and consequently the refrigeration capacity, continuous cooling for adsorber during the adsorption processes is recommended.

- The present modified absorber bed performance achieved a reasonably high COP, therefore it is challenge to be used in multi bed continuous adsorption unit

\section{REFERENCES}

[1] Yongling Z, Study of activated carbon/methanol adsorption refrigeration tube and system integration, M.Sc. thesis, School of mechanical engineering, the University of Adelaide, Australia, January 2011

[2] Chang WS, Wang CC, Shieh CC, Experimental study of a solid adsorption cooling system using flat-tube heat exchangers as adsorption bed, Applied Thermal Engineering 27 (2007), pp. 2195-2199

[3] M. Louajari, A. Mimet, A. Ouammi, Study of the effect of finned tube adsorber on the performance of solar driven adsorption cooling machine using activated carbon-ammonia pair, Appl. Energy 88 (2011) 690-698

[4] Kasidid A, Development of a microchannel device for adsorption cooling application, M.Sc. thesis , Oregon State University, US 2009.

[5] Mitsuhiro K, Takeshi U, Ryo F, Jun K, Fujio W ,Noriyuki K, Masanobu H, Cooling output performance of a prototype adsorption heat pump with fin-type silica gel tube module, Applied Thermal Engineering 28 (2008), pp. 87-93

[6]Wanga DC, Wua JY,. Xiaa ZZ, Zhaia H,. Wanga RZ,. Doub WD, Study of a novel silica gel-water 
adsorption chiller. Part I". Design and performance prediction, International Journal of Refrigeration 28(2005), pp.1073-1083

[7] Wanga DC, Wua JY,. Xiaa ZZ, Zhaia H,. Wanga RZ,. Doub WD, Study of a novel silica gel-water adsorption chiller. Part II".Experimental study, International Journal of Refrigeration 28(2005), pp.1084-1091

[8] Zaizhong X., Wang D, Zhang J, Experimental study on improved two-bed silica gel-water adsorption chille, Energy Conversion and Management 49 (2008), pp.1469-1479

[9] Yanlin Li, Simulation of a 4-bed silica gel-water adsorption chiller, M.Sc. thesis, national university of Singapore 2003.

[10] Li Yong and Ruzhu Z. Wang. "Adsorption Refrigeration: A Survey of Novel Technologies". Recent Patents on Engineering 2007, 1, pp. 1-21.

[11] Wang RZ and Oliveira RG, Adsorption refrigeration -An efficient way to make good use of waste heat and solar energy, International Sorption Heat Pump Conference, USA, ISHPC$101 \mathrm{~K}-2005$.

[12] Bidyut Baran Saha, Anutosh Chakraborty, Shigeru Koyama, Yu I. Aristov, A new generation cooling device employing $\mathrm{CaCl} 2$-insilica gel-water system, International Journal of Heat and Mass Transfer 52 (2009), pp.516-524

[13] BrianK.Parsons, Ahmad A.pesaran, Desikan Bharathan and Benjamin Sheipuk., Evaluation of thermally activated heat pump/desiccant air conditioning systems and componenets, SERI/TR, pp.252-3116, April 1987

[14] Boelman EC, Saha BB, Kashiwagi T., Experimental investigation of a silica gel-water adsorption refrigeration cycle - the influence of operating conditions on cooling output and COP, ASHRAE Trans Res 1995, 101(2), pp.358-366

[15] Yang Q.R, Wang DC,.shi ZX, Tian XL, Zhang J.C, Wu J.Y., Experimental research on novel adsorption chiller driven by low grade heat source".Science direct, Energy Conversion and Management 48 (2007), pp.2375-2381

\section{NOMENCLATURE}

$\mathrm{Q}_{\mathrm{C}} \quad$ Refrigeration capacity (W)

$\mathrm{Q}_{\mathrm{h}} \quad$ Heating power (W)

COP Coefficient of performance

SCP Specific cooling power $(\mathrm{W} / \mathrm{kg})$

$\mathrm{P} \quad$ Pressure (bar)

t Time, $(\mathrm{S})$

$\mathrm{T} \quad$ Temperature $(\mathrm{K})$

m Mass

$\dot{\mathrm{m}}$ Mass flow rate, $\mathrm{kg} / \mathrm{s}$

\section{SUBSCRIPTS}

S Solid phase, silica gel

sat Saturation

ads Adsorption

$\begin{array}{ll}\text { reg } & \text { Regeneration } \\ \text { eva } & \text { Evaporator } \\ \text { in } & \text { Inlet } \\ \text { out } & \text { Outlet } \\ \text { w } & \text { Water } \\ \text { a } & \text { Air }\end{array}$

Table 1 Comparisons of the experimental results between this work and the former works at a typical working

\begin{tabular}{|c|c|c|c|c|}
\hline \multirow{2}{*}{ Reference } & \multicolumn{2}{|c|}{$\begin{array}{c}\text { Operating } \\
\text { Temperature } \\
\end{array}$} & \multirow{2}{*}{$\begin{array}{l}\mathrm{T}_{\mathrm{des}} \\
\left({ }^{\circ} \mathrm{C}\right)\end{array}$} & \multirow{2}{*}{ COP } \\
\hline & $\begin{array}{r}\mathrm{T}_{\text {eva }} \\
\left({ }^{\circ} \mathrm{C}\right) \\
\end{array}$ & $\begin{array}{l}\text { Tads } \\
\left({ }^{\circ} \mathrm{C}\right) \\
\end{array}$ & & \\
\hline $\begin{array}{c}\text { Boelman et } \\
\text { al [14] }\end{array}$ & 16 & 20 & 70 & 0.43 \\
\hline Present work & $\begin{array}{l}16.5 \\
16.5\end{array}$ & $\begin{array}{c}21.5 \\
20\end{array}$ & $\begin{array}{l}70 \\
60\end{array}$ & $\begin{array}{l}0.46 \\
0.56\end{array}$ \\
\hline \multirow{2}{*}{$\begin{array}{c}\text { Yang et al } \\
\text { [15] }\end{array}$} & 20 & 28 & 80 & 0.32 \\
\hline & 20 & 28 & 70 & 0.29 \\
\hline Present work & 20 & 28 & 60 & 0.55 \\
\hline
\end{tabular}

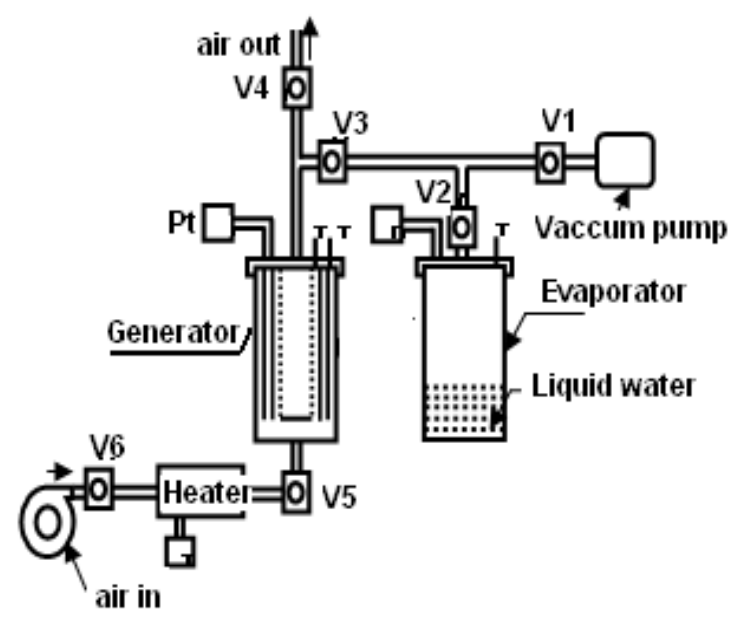

Fig. 1. Test rig schematic diagram

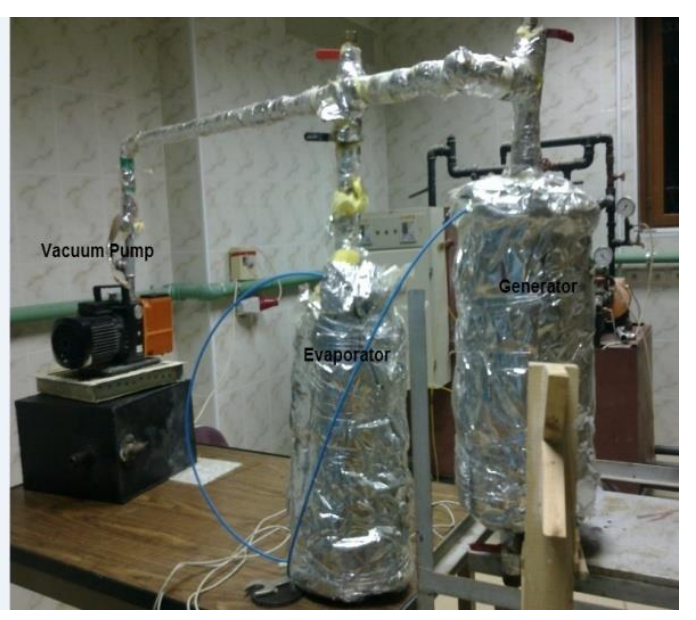

Fig. 2. A photograph of the experimental test rig 


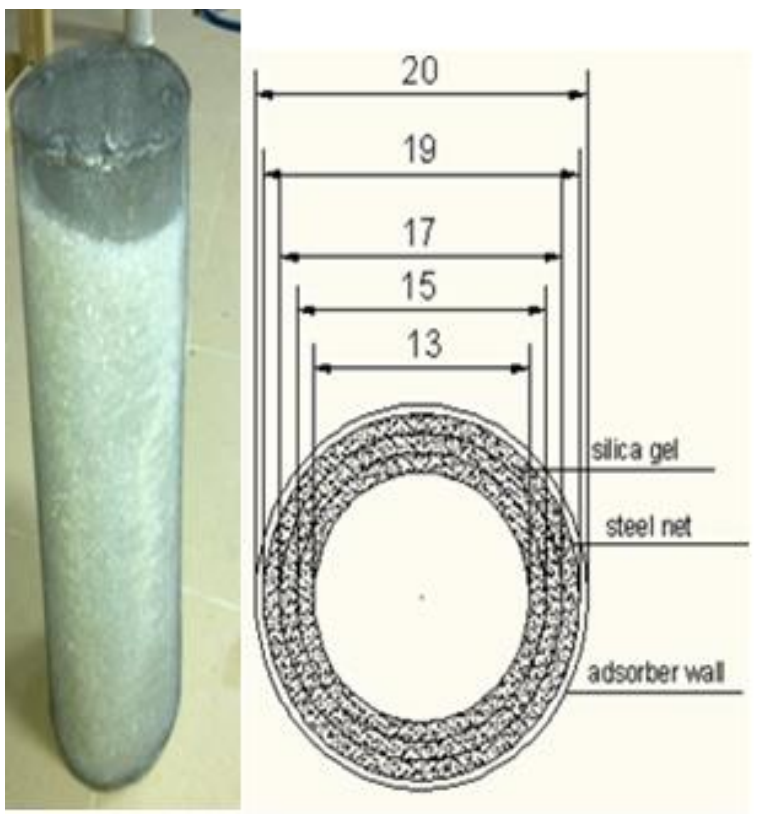

Fig. 3. Steel net cylinders unit

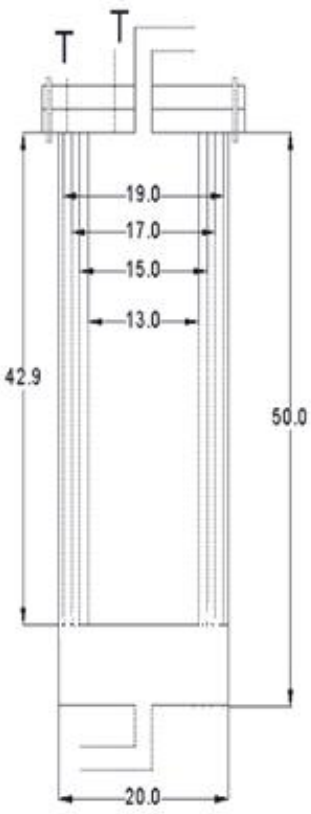
(a)Dimentions of the adsorber
(b) Schematic diagram of the adsorber

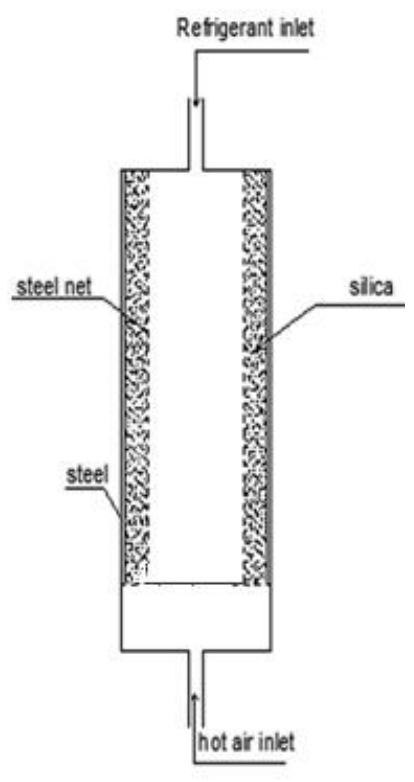

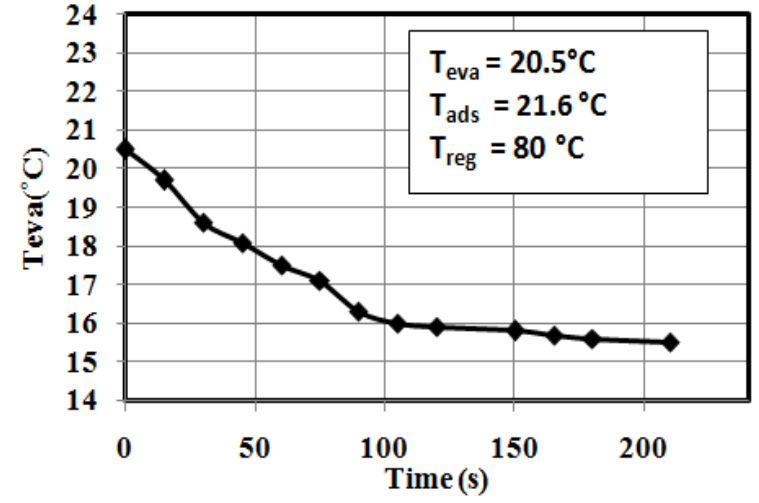

Fig. 5. Refrigerant temperature variations in the evaporator

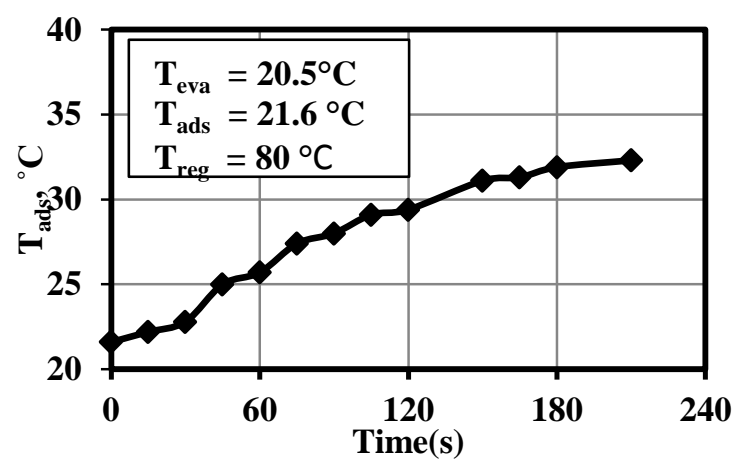

Fig. 6. The adsorber temperature variation during adsorption process.

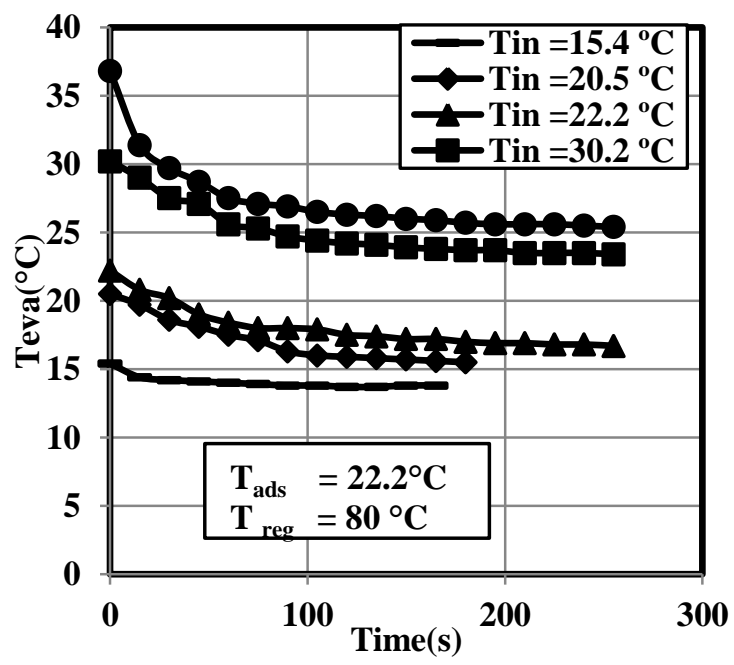

Fig. 7. Variation of water temperature with time at different initial evaporator water temperature

Fig. 4. The generator design 


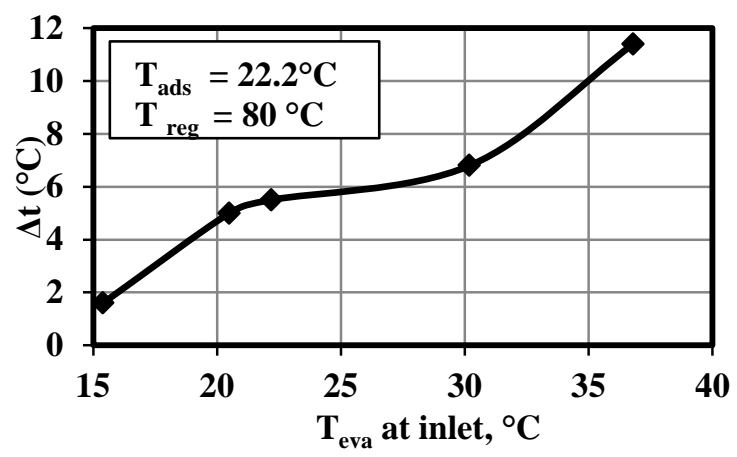

Fig. 8. Effect of initial water temperature on water temperature difference in the evaporator

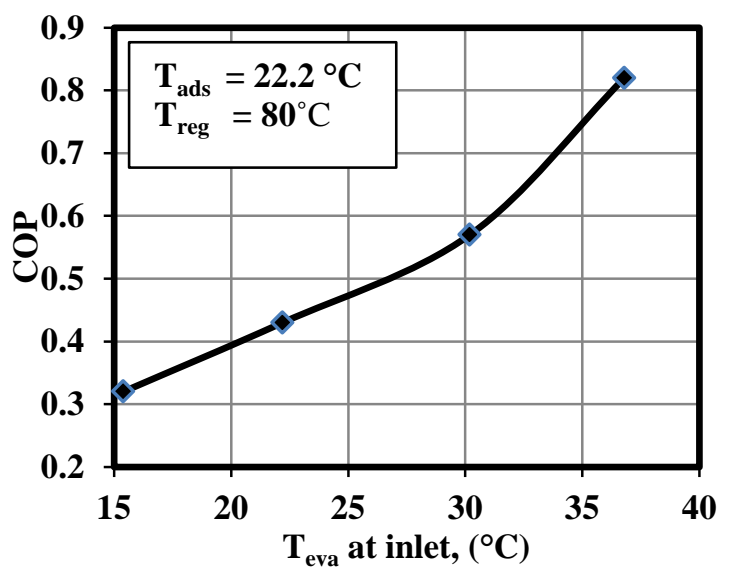

Fig. 9. Effect of evaporator inlet water temperature on COP

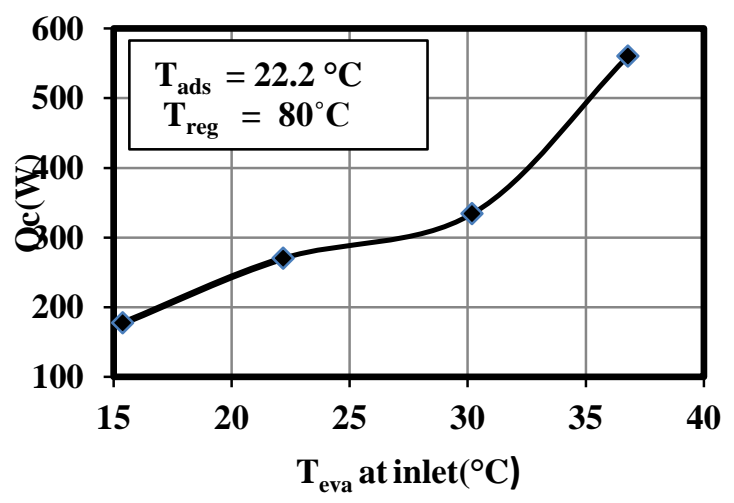

Fig. 10. Effect of evaporator inlet water temperature on cooling capacity

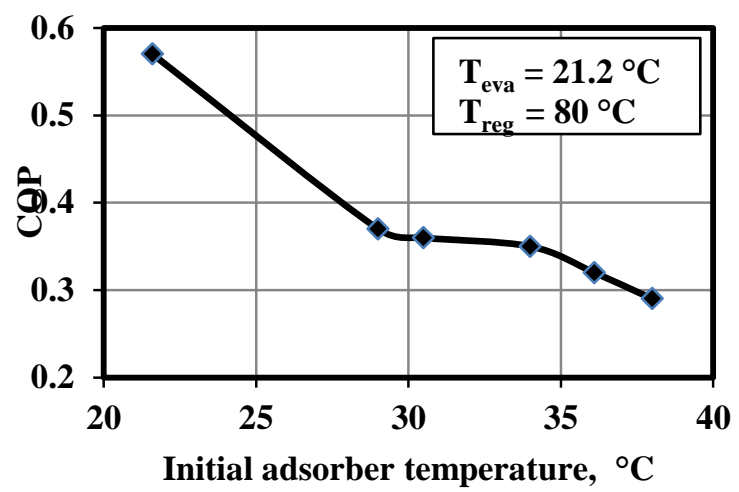

Fig. 11. Effect of initial adsorber temperature on COP

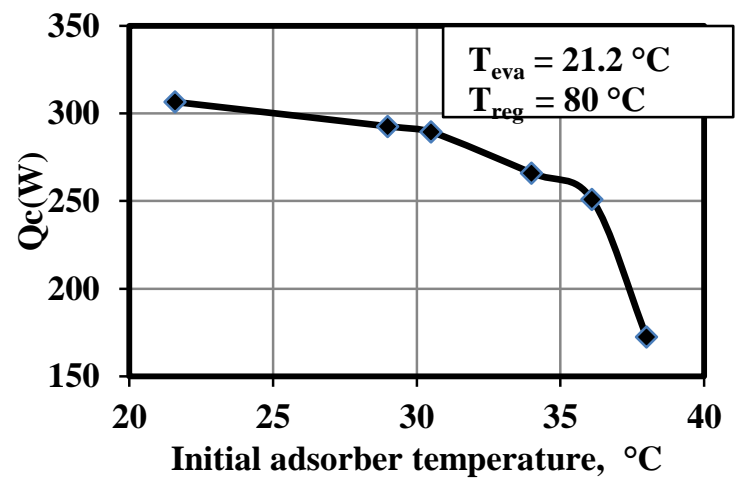

Fig.12. Effect of initial adsorber temperature on Qc

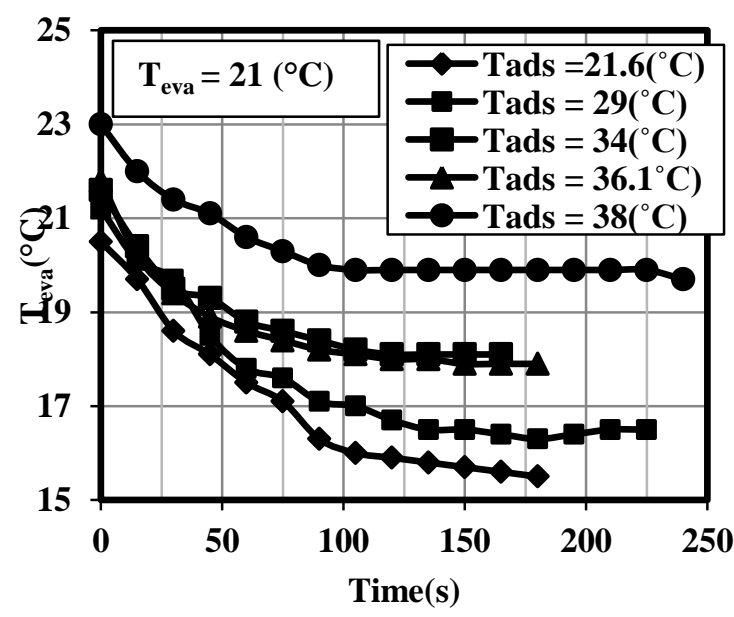

Figure 13 Effect of adsorption temperature on evaporator water temperature during adsorption time 


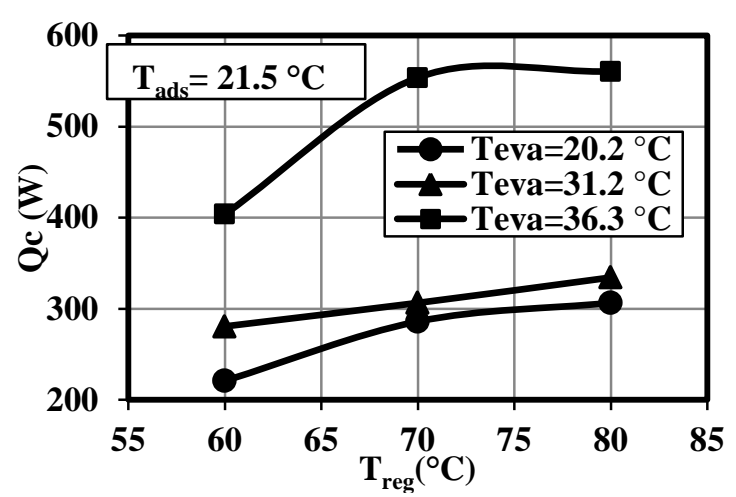

Fig. 14. Effect of regeneration temperature on cooling capacity

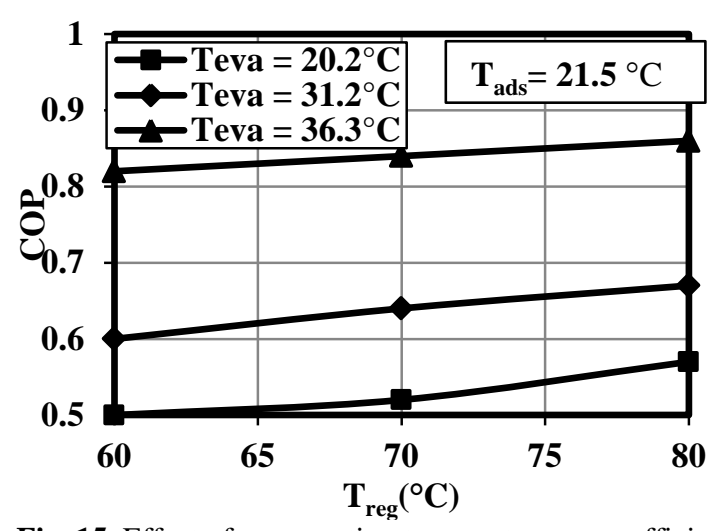

Fig. 15. Effect of regeneration temperature on coefficient of performance

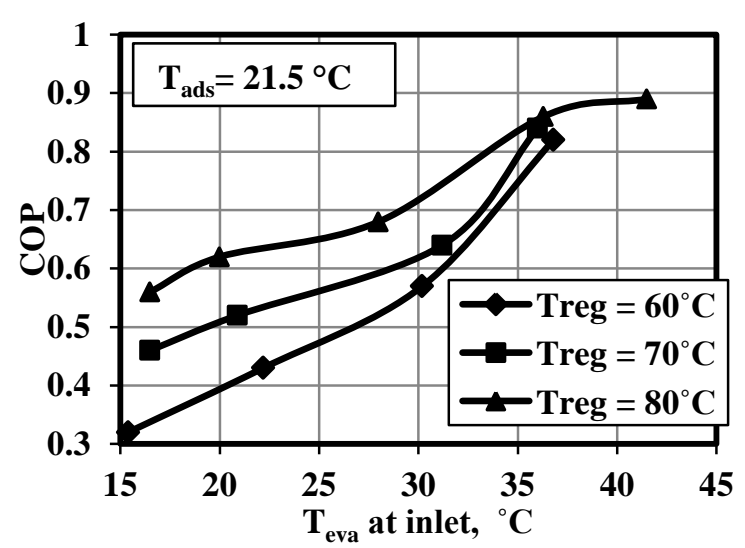

Fig. 16. Effect of evaporator inlet water temperature on the $\mathrm{COP}$ at different regeneration temperatures

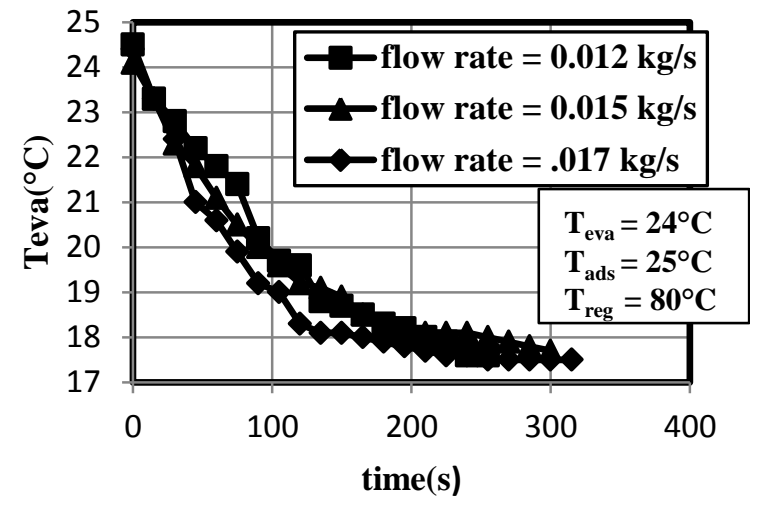

Fig.17. Effect of hot air flow rate on the evaporator water temperature 